\title{
The Present Perfect as an Epistemic Modal
}

\author{
Roumyana Izvorski \\ University of Pennsylvania
}

\section{The Present Perfect-Evidential Connection}

In a number of languages from various language families, the morphology of the present perfect or a form historically derived from the present perfect, expresses a particular evidential category, one that indicates the availability of indirect evidence for the truth of a proposition (the exact interpretation is discussed in more detail in the next two sections). ${ }^{1}$ The phenomenon, to which I give the name PERFECT OF EVIDENTIALITY (PE), is illustrated in (1):

a. Gel -miş -im.

Turkish come PERF 1SG

b. Az sâm došâl. I be-1SG, PRES come-P.PART

Bulgarian

c. Jeg har kommet. I have-1SG, PRES come-P.PART

Norwegian

'I have come.'

(PRESENT PERFECT) and/or

'I apparently came.'

(1a) is an example of the historical connection between present perfect and evidential in Turkish: the inflected verb has the morphology of the present perfect but in the contemporary language the sentence is interpreted only as a perfect of evidentiality (i.e. indirect evidential) ( $\mathrm{mIs}$ still has a perfect meaning in non-finite environments as well as in the presence of future or past tense, as discussed later on). The sentences in $(1 \mathrm{~b}, \mathrm{c})$ are ambiguous between present perfects and perfects of evidentiality. In English, sentential modification by apparently renders quite closely the second interpretation. In both English and in the languages with the perfect of evidentiality, the indirect evidential interpretation allows both a report and an inference reading; i.e. both Apparently $p$ and $p-P E$ are interpreted as either $I t$ is said that $p$ or as $I$ infer that $p^{2}$. Note that in the case of the perfect of evidentiality, the morphology of the present perfect alone brings about the evidential interpretation; there is no QUOTATION- or INFERENCE-morpheme and no embedding under verbs of saying or of inference. Furthermore, the interpretation is independent of the particular form of the present perfect: synthetic, as in (1a), formed with a be-auxiliary, as in (1b), or with a have-auxiliary, as in (1c). ${ }^{3}$

Because the perfect of evidentiality is observed in languages that are not all genetically related or geographically proximate, it is quite unlikely that the present perfect-evidential connection is just a case of accidental syncretism. In fact, it is possible to rule out on empirical grounds the possibility that the specific forms involved are lexically ambiguous. There are at least four counterexamples to a potential claim that the PE-morphology, e.g. $\mathrm{mIs}$ in Turkish (or auxiliary plus past participle in languages with analytic perfects), is simply ambiguous between a PERFECT and an INDIRECT EVIDENTLAL interpretation. In the case of the English apparent/supposed/alleged/reported, which have report and/or inference as part of

(C) 1997 by Roumyana Izvorski

Aaron Lawson (ed), SALTVII, 222-239, Ithaca, NY: Cornell University. 
their lexical meaning, this meaning is always present regardless of the syntactic configuration in which the morphemes appear: as modifier adjectives, adverbials, or embedding (finite or not) predicates. To see this, consider the sentences below:

(2) a. John is an apparent/supposed/alleged/reported thief.

b. John is apparently/supposedly/allegedly/reportedly a thief.

c. John appears/is supposed/is alleged/is reported to be a thief.

d. For it to appear that John is a thief one would have to tell a lot of lies.

In the languages with the perfect of evidentiality, however, the evidential interpretation is unavailable in any other syntactic configuration but the one identical to (or derived from) the present perfect. In Turkish, for instance, when $-m I_{s}$ forms NP-modifying participles, the interpretation of indirect evidential is absent. Consider (3) (from Slobin and Akşu 1982):

(3) öl-müş adam

dead man

$=$ 'dead man'

$\neq$ 'a man who is apparently dead'

Similarly, when $-m I_{S}$ is involved in the formation of the past or the future perfect, the interpretation of evidentiality does not arise (cf. (4) and (5)).

(4) Gel -miş -tim.

come PERF 1SG.PAST

$=$ 'I had come.'

f 'I apparently came/had come.'

(5) Gel -miş ol -acak -1m.

come PERF be FUT 1 SG

$=$ 'I will have come.'

$\neq$ 'I will apparently come.'

Finally, in non-finite clauses the presence of -mIs is not enough to bring about the indirect evidential interpretation:

(6) Kitap yaz -mış ol -mak büyük bir başarı.

book write PERF be INF big a achievement.

$=$ 'To have written a book is a big achievement.'

\# 'To have apparently written a book is a big achievement.'

In sum, the facts about the available interpretation for the past and future perfects, the non-finite perfect, and for the adjectival perfect participle argue against the possibility that the meaning of indirect evidentiality is a lexical idiosyncrasy of the morphemes involved (the same facts obtain for the languages with analytic perfects). Thus we can definitively rule out the possibility that what we have at hand is simply an accidental syncretism (unlikely as this hypothesis was, given the cross-linguistic distribution of the phenomenon). We can furthermore draw two conclusions: (i) the anchoring of the perfect meaning to the present tense is 
significant for deriving the indirect evidential interpretation, and (ii) the reason for the morphological syncretism must be sought in the semantics of the present perfect and the indirect evidential; i.e. the two must share some feature(s) which receive identical morpho-phonological realization. The goal of this paper is to first provide a semantics for indirect evidentials and then to identify the elements in the semantics of the present perfect, as composed of present tense and perfect aspect, that give rise to the interpretation of indirect evidentiality.

The phenomenon of the perfect of evidentiality is of interest for a number of reasons. First, the syncretism of forms poses a problem for theories treating tense, aspect and modality as independent. A theory which integrates these, identifying common elements in their semantics and representing these elements syntactically, is clearly to be preferred. Such a conclusion is further strengthened by the fact that the present perfect-evidential connection is not the only example of a morphological collapse of temporal and modal categories. A more familiar case in the literature is the counterfactual role of past tense (Isard 1974, Lyons 1977; cf. Iatridou 1996 for an analysis in terms of a common function taking time intervals or possible worlds as arguments). The existence of both the past-counterfactual and present perfect-evidential links suggests that there is a general pattern of integration between temporal and modal categories. Finally, the phenomenon of the perfect of evidentiality and evidentiality itself as a grammatical category are virtually unknown in the theoretical literature; setting the beginning of their formal investigation, therefore, is of interest for theories of syntax-semantics and syntax-morphology mappings in the domain of modality.

The rest of the paper is organized as follows. In section 2 I discuss evidentiality as a linguistic category. In section 3 I examine the meaning of indirect evidentials, like the perfect of evidentiality and like English apparently. Essentially, I analyze them as epistemic modals with a universal modal force and a more restricted domain of quantification than that of 'ordinary' epistemic operators. Section 4 discusses the temporal and aspectual interpretation of PE statements and establishes that the present perfect morphology has a strictly modal function and does not contribute to the temporal and aspectual specification of the core proposition. Section 5 proposes an analysis of the semantic contribution of the present perfect.

\section{Evidentiality}

Evidentiality is a linguistic category encoding speaker-oriented qualifications of propositions along two dimensions: (i) in terms of the evidence they are based on, e.g. DIRECT (visual/auditory, etc.) or INDIRECT (report or inference), and (ii) with respect to the speaker's commitment to their truth ((dis)belief/agnosticism) (cf. Chafe and Nichols 1986 for discussion and case studies). ${ }^{4}$ The two dimensions whether the proposition is based on perceptual evidence and whether the speaker believes in its truth - are logically independent. Yet natural language typically treats propositions based on perceptual evidence on the part of the speaker as propositions asserted by the speaker to be true; similarly, if a speaker marks a proposition as based not on first-hand evidence, he or she typically expresses non-commitment to the truth of the proposition. This is why it is more usef ul to think of the terms DIRECT and INDIRECT (which appear to be the generally accepted ones in the literature on evidentiality) as making a distinction based not on whether or not the evidence is 
perceptual, but on whether or not the evidence justifies the speaker's belief in a proposition. $^{5}$

Many (perhaps all) languages have a way of expressing the status of the speaker's presentation of the truth of propositions. Some languages express evidential distinctions lexically. English, for example, encodes evidentiality by using embedding verbs and different adverbials to express various types of evidence for the truth of a particular proposition and various degrees of speaker's commitment to that truth. To illustrate with an example, the proposition $p$, John was singing, can be lexically modified to reflect the speaker's source of evidence and/or attitude towards its validity. Thus the sentences in (7a) express the fact that the speaker has perceptual evidence for the truth of $p$ whereas (7b) and (7c) mark the evidence as indirect, the sentences being interpreted as reports of $p$ or as inferences about $p$. The report or inference interpretation is lexically determined in (7b), i.e. the sentences are not ambiguous with respect to the type of evidence involved; whereas apparently in (7c) is underspecified as to the exact type of indirect evidence.

(7) a. I saw/heard John singing. (direct evidence: visual/auditory)

b. I see/hear (that) John was singing. (indirect evidence: inference/report)

c. John was apparently singing. (indirect evidence: inference or report)

In addition to expressing the source of evidence, the sentences in (7) also trigger inferences about how certain the speaker is of the truth of $p$. The sentences in (7a) under normal circumstances entail that the speaker has a justified belief in $p$, i.e. knows $p$, or more accurately, has come to know $p$ (they also entail $p$, for that matter). This, of course, is not a logical entailment, as it is quite easy to imagine situations in which the speaker's perceptions are often misleading and the speaker knows it; in such situations ( $7 \mathrm{a}$ ) would entail neither $p$, nor that the speaker believes $p$. Regarding $(7 \mathrm{~b}, \mathrm{c})$, there is a difference in the interpretation available to reports and inferences with respect to the speaker's attitude to the truth of $p$. Whereas reports simply express that the speaker is not committed to the truth of $p$, i.e. these sentences do not entail that the speaker believes $p$ (nor do they entail $p$ ), inferences trigger the interpretation that the speaker comes to believe $p$, but on the basis of evidence insufficient to justify knowledge. (Note that in the situation just described above, where the speaker knows that his perceptions are not always reliable, it is appropriate to use an indirect evidential upon seeing or hearing John sing.)

While languages like English express evidentiality lexically, other languages grammaticize evidentiality in their inflectional morphology or in their complementizer system (cf. Willett 1988, Palmer 1986 for examples). Languages differ in how detailed a distinction of evidential categories they make (cf. note 4). According to Willett (1988), it is quite common for languages to have grammaticized only a two-way distinction between direct and indirect evidence, and typically, it is the indirect evidential that is morphologically marked. This is exactly the case in the languages with the perfect of evidentiality: the PE-morphology marks both reports and inferences and sentences without the PE-morphology are interpreted as based on direct evidence, i.e. on evidence justifying belief. 


\section{Semantics for Indirect Evidentials}

As became clear in the previous section, indirect evidentials, like the perfect of evidentiality or English apparently, are semantically propositional operators. Sentences of the form Evp, where Ev stands for the indirect evidentiality operator, result in the interpretation that $p$ is possible, very likely, or necessary relative to the knowledge state of the speaker. In other words, the indirect evidentiality operator $\mathrm{EV}$ is an epistemic modal. ${ }^{6}$ Under the report interpretation, depending on the source, Ev $p$ can have a variable modal reading, anywhere between weak possibility to necessity, i.e. in its report reading, (1) can mean I may have come, I probably came, or I must have come, (given what $X$ says). The more trustworthy $X$ is, the closer to universal the modal interpretation. The modal force of the Ev operator in the case of the inferential interpretation is universal, i.e., in its inference reading, (1) is interpreted along the lines of I must have come. This is so because in stereotypical contexts, reasoning is considered a highly reliable source of (indirect) evidence.

It is clear that the variability in the modal interpretation of indirect evidentiality statements comes from context; it is therefore possible to give a uniform interpretation to the EV-operator. My proposal about the semantic contribution of $\mathrm{EV}$ is summarized in (8):

(8) The Interpretation of Evp:

a. Assertion: $\square \mathrm{p}$ in view of the speaker's knowledge state

b. Presupposition: Speaker has indirect evidence for $\mathrm{p}$

In other words, Ev is a universal epistemic modal with a presupposition of available indirect evidence for the truth of the proposition it modifies.

In explicating the meaning of the epistemic modal operator EV I adopt Kratzer's (1991) enriched system of possible worlds semantics. Modal words are analyzed as existential or universal quantifiers over possible worlds. In addition to contributing a modal (quantificational) force, modals are associated with two contextually determined parameters: a MODAL BASE and an ORDERING SOURCE, both functions from worlds to sets of propositions. The epistemic modal base assigns to every possible world $w$ the set of propositions that are known in $w$. Since in possible worlds semantics propositions are identified with the sets of worlds in which they are true, ultimately the modal base specifies for every world a set of worlds accessible from it, epistemic accessibility being defined as compatibility relative to a knowledge state. The ordering source, an innovation to possible worlds analysis of modality, imposes a particular ordering among the accessible worlds determined by the modal base. Worlds can be ordered, for instance, with respect to how close they are to what the normal course of events is in a given world. Such a STEREOTYPICAL ordering source is responsible for the statement in $(9 \mathrm{~b})$ being interpreted as weaker than the one in $(9 a)$, rather than implying it (examples from Kratzer 1991):

(9) a. She climbed Mount Toby.

b. She must have climbed Mount Toby.

If must was interpreted simply as a universal quantifier over the worlds accessible from $w$, then (9b) would indeed entail (9a) in $w$. Taking into account the stereotypical 
ordering source prevents this undesirable result. The ordering source assigns to every world the set of propositions that constitute what is normally the case in that world, and imposes an ordering on the accessible worlds with respect to that set of propositions. Universal quantification is then only over the set of closest worlds. Since it is not necessary for $w$ to be an element of the set of worlds that come closest to what normally happens in $w,(9 b)$ will not entail (9a) in $w$.

This brief outline of Kratzer's treatment of epistemic modality will be sufficient as a framework for discussing indirect evidentiality formally. In short, I propose that an ordering source, determined by the speaker's beliefs regarding the available evidence, is responsible for restricting the set of epistemically accessible worlds in the domain of quantification. This results in having Ev $p$ statements not entail $p$, much like the case of $(9 \mathrm{a}, \mathrm{b})$, while providing for variability of inferences with respect to 'ordinary' epistemic modals. But first, before going into the details of a more formal account, let us convince ourselves that the proposal in (8) is indeed justified.

From the definition in (8) we can see that what distinguishes Ev from the 'ordinary' epistemic modal must is the presupposition of available indirect evidence. Often in treatments of epistemic modality, one finds that accessibility relations between possible worlds are determined on the basis of what the available evidence $i s$, with no finer distinctions being made between the kinds of evidence underlying inferences about propositions whose truth value is unknown. It turns out, though, that distinguishing between the kinds of evidence involved in epistemic reasoning is important for natural language. Compare the sentences in (10) (the examples in (11) are their perfect of evidentiality equivalents ${ }^{7}$ ):

(10) Knowing how much John likes wine...

a. ...he must have drunk all the wine yesterday.

b. \#...he apparently drank all the wine yesterday.

(11) Knowing how much Ivan likes wine...

a. ...toj trjabva da e izpil vsičkoto vino včera.

he must is drunk all-the wine yesterday

'...he must have drunk all the wine yesterday.'

b. \#...toj izpil vsičkoto vino včera.

he drunk-PE all-the wine yesterday

'... he apparently drank all the wine yesterday.'

We can see that the proposition John likes wine a lot is sufficient to justify the use of epistemic must in (10a) but not the use of apparently in (10b). The indirect evidential requires that there is, roughly speaking, some observable result of John's drinking all the wine, perhaps many empty bottles or someone's account of the event of drinking.

The same point is illustrated in the contrast between (12) and (13). The speaker can continue an epistemic statement must $p$ with acknowledgment that she or he lacks evidence for $p$, but this is not possible in the case of EVp. Of course, must still requires the existence of some set of known propositions to serve as a premise for the epistemic inference and this is why the second continuation in (12) is ruled out. 
(12) A: John must have drunk all the wine.

$A^{\prime}$ : But I have no evidence for that.

$A^{\prime}$ : (\# But I have no reason for believing that.)

(13) A: Ivan izpil vsičkoto vino včera.

Ivan drunk-PE all-the wine yesterday

'Ivan apparently drank all the wine yesterday.'

$\mathrm{A}^{\prime}$ : \# But I have no evidence for that.

In sum, the requirement that there be available evidence is indeed part of the interpretative contribution of $\mathrm{EV}$, in contrast to epistemic must. Next, it can be shown that the evidence can only be indirect, i.e. it cannot be sufficient to justify a belief in the core proposition. Neither the perfect of evidentiality in (14) nor its English equivalent with apparently accepts following assertions to the effect that the speaker has prior belief, or has evidence justifying a belief, that Maria kissed Ivan.
A: Maria celunala Ivan.
Maria kiss-PE Ivan
'Maria apparently kissed Ivan.'
A': \# (Actually) I witnessed it./ \# (Actually) I know that for a fact.

It is reasonable at this point to ask the question: Could it be the case that the requirement that the evidence only be indirect is simply a cancellable implicature? In other words, given that the speaker had a choice to assert $p$, by not doing so she or he indicates that no stronger evidence is available to her/him. Conversational implicatures of this sort are cancellable, though, which, as we have just seen in (14), is not the case with the perfect of evidentiality and apparently. ${ }^{8}$ Having concluded that the inference of available indirect evidence is not a cancellable implicature, it is still necessary to convince ourselves that it is also not part of the assertion of Evp. The standard negation tests show that the evidential interpretation is a presupposition. Negating perfect of evidentiality statements and statements with apparently results in the interpretation that the core proposition is being negated, not the availability of indirect evidence: ${ }^{9}$

(15) a. Apparently, Ivan didn't pass the exam. ${ }^{10}$

b. Ivan ne izkaral izpita.

Ivan not passed-PE the-exam

$=$ 'Ivan didn't pass the exam (it is said/I infer).'

$\neq$ 'It is not the case that $\{$ it is said/I infer $\}$ that Ivan passed the exam'.

Similarly, contradicting an assertion Ev $p$, as in (16), challenges $p$, not the evidence $p$ is based on:
A: Ivan izkaral izpita.
Ivan passed-PE the-exam

Apparently, Ivan passed the exam. 


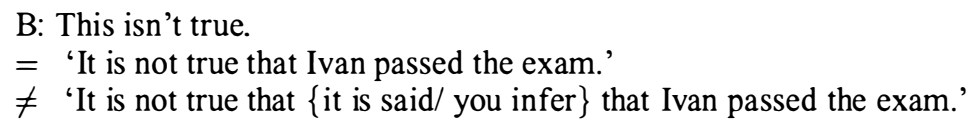

To summarize what has been accomplished so far, we have seen that the indirect evidentiality operator has the assertion of a modal and is associated with a presupposition that the core proposition is based on indirect evidence. The last points that remain to be discussed, concerning the semantic contribution of EV, as outlined in (8), are the modal force of $E v$ and the epistemic nature of the modal base. Let us consider the former issue first. Presumably, it can be argued that at least in the case of apparently, the universal force is lexically specified. I don't see a way of ruling out this possibility, but I have several considerations against it. One can illustrate the universal specification of modals like must and necessarily by comparing them to their duals may/can and possibly, respectively. The same cannot be done for apparently, so adopting a lexical specification approach amounts to little more than a stipulation. Another argument comes from the analysis of attitude verbs like know, believe, wish as modal operators; adopting such an account results in treating these verbs as universal quantifiers over worlds compatible with the speaker's knowledge state, believes, or desires. ${ }^{11}$ Instead of saying that these verbs, too, are lexically specified for their universal force, a better approach will be to find a common explanation for the fact that the various operators, which are not in any obvious way lexically specified to mean must/necessarily, end up being interpreted as universal quantifiers. Finally, in the case of the PE morphology, the goal of the present proposal is to derive the meaning of indirect evidentiality compositionally, i.e. by identifying a common underspecified representation for the present perfect and for the indirect evidential. Building a universal quantifier into the underspecified set of features will interfere with the semantics of the present perfect. $^{12}$

A second attempt at accounting for the universal force of indirect evidentials is to say that a null necessity operator co-occurs with the PE morphology and with apparently, i.e. that $E v$ is not contributed by these elements but is a separate nonovert operator. Yet this will amount to denying the modal role of apparently and of the PE morphology altogether and will raise the question of what their interpretative function is, if not that of contributing the modality themselves. In section 4, in fact, I present arguments that in PE statements the morphology does not play a temporal or aspectual role, which supports the view that it is the source of the modality.

Thus, the position which I adopt is that only the quantificational force of EV is non-overt; the PE morphology and apparently are obviously lexical, but they only contribute the intensionality and specify the kind of modality involved. A semantic decomposition of the modal is not in itself controversial, it is in fact part of Kratzer's (1991) three-parameter analysis of modality (as involving modal force, modal base, and ordering source); what is novel and more unusual is that the quantificational properties are argued here to be separate from the intensional operator, and that the latter can be lexicalized without the former being expressed overtly.

In the proposal advocated here, the PE morphology and apparently are modal operators whose quantificational force is not specified. Some default mechanism is responsible for determining that force as universal. While I do not have a specific solution as to why the default interpretation is universal, this interpretation should perhaps come as no surprise, considering that the quantificational force of EV is 
not expressed overtly. It is known that non-overt operators tend to have universal interpretation, consider for instance Kratzer's (1986) proposal that conditional clauses be analyzed as restrictors of a covert must, or the idea that there is a generic null operator in generic sentences ${ }^{13}$, or the case of attitude verbs discussed above. Without, of course, being explained, the universal force of $E V$ is at least consistent with that of other non-overt modals.

The epistemic interpretation of EV raises another interesting question. Overt modals typically allow for a range of interpretations: epistemic, deontic, dynamic, etc. It is plausible to suggest, that, in the case of apparently, interpretation relative to knowledge state is lexically specified. In the case of the perfect of evidentiality, however, it is not immediately clear why the epistemic interpretation is the only one available. An interesting hypothesis to pursue is that there is non-trivial affinity between temporal operators and modal operators of the epistemic kind. Some suggestions regarding this issue will be made in section 5 .

Let u s now turn to formalizing the proposal about the semantic contribution of Ev. As noted above, the proposal is set within the general framework of Kratzer (1991). Let $W$ be the set of possible worlds and let $f$ be the function that assigns to every possible world the set of propositions that constitute the available indirect evidence (for the core proposition) in that world. The propositions in $f(w)$ are obviously known in that world but this is a more restricted set than the 'ordinary' epistemic what is known in $w$, since, as we saw in the discussion regarding examples (10)-(13), it is not sufficient for a proposition to be known for it to be considered (indirect) evidence for the core proposition. $f(w)$ may include propositions like Mary says that $p$ or There are empty wine bottles in John's office; the former will yield a report interpretation for EV $p$ and the latter an inference interpretation. The domain of quantification of EV is initially $\bigcap f(w)$, the set of worlds in which all propositions that are considered evidence in $w$, are true.

(17) $\mathrm{f}(\mathrm{w})=\{\mathrm{p}$ : speaker considers $\mathrm{p}$ indirect evidence in $\mathrm{w}\}$

$$
\bigcap \mathrm{f}(\mathrm{w})=\{\mathrm{u} \in \mathrm{W}: \forall \mathrm{p}[(\mathrm{p} \text { is the indirect evidence in } \mathrm{w}) \rightarrow \mathrm{u} \in \mathrm{p}]\}
$$

The actual domain of quantification is restricted by the ordering source. Let $g$ be the function that assigns to every possible world the set of propositions representing the speaker's beliefs concerning the available indirect evidence (f or the core proposition) in that world. This set may include propositions like Normally, Mary is reliable as a source of information or If there are empty wine bottles in someone's office, that person has drank the wine. The set of propositions $g(w)$ imposes an ordering $<_{g(u)}$ on $W$ such that for all $u, v \in W, v$ is closer to the ideal set by $g(w)$ than $u$ is, iff all propositions in $g(w)$ which are true in $u$ are true in $v$ and there are propositions in $g(w)$ which are true in $v$ and which are not true in $u .^{14}$

(18) $\mathrm{g}(\mathrm{w})=\{\mathrm{p}$ : speaker believes $\mathrm{p}$ with respect to the indirect evidence in $\mathrm{w}\}$ For $\forall \mathrm{u}, \mathrm{v} \in \mathrm{W}: \mathrm{v}<_{g(w)} \mathrm{u}$ iff $\{\mathrm{p}: \mathrm{p} \in \mathrm{g}(\mathrm{w}) \wedge \mathrm{u} \in \mathrm{p}\} \subset\{\mathrm{p}: \mathrm{p} \in \mathrm{g}(\mathrm{w}) \wedge \mathrm{v} \in \mathrm{p}\}$

An indirect evidentiality statement Evp is true in a world $w$ with respect to the conversational backgrounds provided by $f$ and $g$, iff $p$ is true in all worlds accessible from $w$ which come closest to the ideal represented by the speaker's beliefs regarding the available indirect evidence in $w$.

$$
\begin{aligned}
& \llbracket \mathrm{EV} p \rrbracket^{f, g}=\left\{\mathrm{w} \in \mathrm{W}: \forall \mathrm{u} \in \mathrm{W}\left[\left(\mathrm{u} \in \cap \mathrm{f}(\mathrm{w}) \wedge \neg \exists \mathrm{v} \in \mathrm{W}\left(\mathrm{v} \in \cap \mathrm{f}(\mathrm{w}) \wedge \mathrm{v}<_{g(w)} \mathrm{u}\right)\right) \rightarrow\right.\right. \\
& \mathrm{u} \in \mathrm{p}]
\end{aligned}
$$


In the discussion above we saw that it is not necessary to build the report and inference interpretations in the meaning of the indirect evidentiality operators PE and apparently. Contextually determined facts that enter the restrictor of the modal operator ensure that the one or the other interpretation arises. It is now necessary to see how the variability in the quantificational force is brought into effect.

Consider first the case where the indirect evidence determining the modal base is a rumor that $p$ and the ordering source concerns the reliability of rumors. If the world of evaluation $w$ is such that rumors are normally right, we will consider those accessible worlds where it is true that there is a rumor that $p$ and that rumors are right; $\operatorname{Ev} p$ will assert that all those worlds are $p$-worlds. The interpreted modal force is therefore close to universal (it is weaker than universal for reasons similar to those discussed in relation to the examples in (9); though rumors are normally right in $w$, the particular rumor need not be). If, however, rumors are considered very unreliable as evidence, the set of accessible worlds where it is true that there is rumor that $p$ and the rumor is right will be very restricted; hence, the resulting interpretation that $p$ is only slightly possible in $w$. Finally, let us consider the inferential interpretation of EV. Let the indirect evidence be the presence of empty wine bottles in John's office and $g(w)$ contain the proposition If there are empty wine bottles in someone's office, that person has drank them. Then the quantification is only over those accessible worlds where there are empty wine bottles in John's office and which come closest to the ideal set by the conditional; all these worlds, then, are asserted to be $p$-worlds. Since the speaker believes $w$ to be such world, it follows that the speaker believes $p$ is true in $w$.

Before we turn to the discussion of the aspects of the semantics of the present perfect that are relevant for the evidential interpretation, it is necessary to establish that the present perfect morphology is playing a strictly modal role and is not responsible for a present perfect interpretation. If indeed perfect of evidentiality sentences were interpreted as ordinary present perfects, as far as tense and aspect are concerned, then arguably, the present perfect morphology would be simply playing its normal function with the modal interpretation coming from somewhere else; or, at most, the present perfect morphology would somehow facilitate the modal interpretation but crucially, would not contribute it. The goal of the next section is thus to illustrate that perfect of evidentiality statements do not have the temporal and aspectual characteristics of present perfects. What this means is that the source of modality is indeed the present perfect morphology.

\section{Temporal and Aspectual Differences Between PE and The Present Perfect}

Even though the indirect evidential employs the morphology of the present perfect, the temporal and aspectual meanings of the two are clearly distinct. (In)compatibility with certain adverbials and with certain types of predicates can serve to test the interpretational differences with respect to tense and aspect between the present perfect and the evidential forms. The conclusion is that the latter always have the temporal and aspectual meaning of their corresponding indicative forms. ${ }^{15}$

Let us consider first the evidential forms of the aorist. Adverbial tests for the perfect-aorist distinction (McCoard 1978, among others) are based on the fact that the aorist in English is incompatible with adverbials like at present, up till now. lately, which are acceptable with the present perfect, whereas the present perfect is 
incompatible with adverbials the aorist is happy to accept like last night, at 3pm, in 1978. Testing the compatibility with adverbials of this kind clearly shows that in languages with the perfect of evidentiality, the present perfect and the evidential forms of the aorist behave differently. The following sentences illustrate this ${ }^{16}$ :

a. Te sa došli (??včera)/ (??snošti)/ (??točno v 3 časa). they are come-P.PART yesterday/ last night/ exactly at 3 o'clock '*They have come yesterday/last night/ exactly at 3 o'clock.'

b. Te došli včera/ snošti/ točno v 3 časa. they come-PE yesterday/ last night/ exactly at 3 o'clock 'They apparently came yesterday/last night/exactly at 3 o'clock.'

We see that there is a contrast in acceptability between the present perfect in $(20 \mathrm{a})$ and the perfect of evidentiality example in $(20 \mathrm{~b})$, the former precluding modification by adverbials like yesterday and the latter allowing such modification. A sharper contrast is provided by the comparison of the present perfect to the evidential forms of the present. These forms behave differently from the present perfect in their compatibility with moment-of-speech oriented adverbials like right now, at this very moment. This is illustrated in the following sentences:

a. Toj e pišel pismo (*točno sega)/ (*točno v tozi moment). he is written-P.PART letter right now/ right in this moment '*He has written a letter right now/ at this very moment.'

b. Toj pišel pismo točno sega/ točno $v$ tozi moment. he written-PE letter right now/ right in this moment 'He is apparently writing a letter right now/ at this very moment.'

As the perfect of evidentiality statement in $(21 \mathrm{~b})$ receives a present temporal specification, it is compatible with adverbials like right now.

Another telling case about the difference in interpretation between the present perfect and the perfect of evidentiality is compatibility with individuallevel predicates. Individual-level predicates are known to be incompatible with the perfect (when unmodified) ${ }^{17}$. Hence the ungrammaticality of the following sentence as a present perfect but its acceptability as a perfect of evidentiality:

Dve pljus dve $(* e) \quad$ bilo ravno na četiri.

two plus two (be-3sG) been equal to four

'*Two plus two has equaled four.'

'Two plus two apparently equals/equaled four.'

Einstein-sentences provide another test for the temporal and aspectual interpretation of perfect of evidentiality statements. As noted in the literature on aspect, the present perfect is incompatible with topics that for one reason or another do not conform to a requirement of current relevance (cf. McCoard 1978) or participant property at reference time. In particular, it has been observed that sentences like (23a), in contrast to the aorist (cf. (23b)), are unacceptable on a reading where Einstein is the topic, since Einstein is no longer alive. (The present perfect is acceptable on a reading where Princeton is the topic of the sentence.) 
(23) a. \# Einstein has visited Princeton.

b. Einstein visited Princeton.

Consider now (24). The fact that the perfect of evidentiality is fully acceptable where the present perfect fails in producing a grammatical sentence, means that the perfect of evidentiality does not receive the temporal and aspectual interpretation of a present perfect.

(24) Ajnštajn (\#e) posetil Prinstân.

Einstein (be-3SG) visited Princeton

'\# Einstein has visited Princeton.'

'Einstein apparently visited Princeton.'

To sum up the findings of this section, the evidential present and aorist, both formed morphologically like the present perfect, do not receive the interpretation of a present perfect but have the temporal and aspectual interpretation of indicative present and aorist, respectively. Therefore, in perfect of evidentiality statements, the morphology of the present perfect does not play its usual temporal-aspectual role; instead its contribution is that of an epistemic modal. The next section aims to provide a semantic explanation for the modal function of the present perfect.

\section{The Contribution of the Present Perfect}

Before going into the details of my proposal about the semantic contribution of the present perfect to the interpretation of indirect evidentiality, I will briefly review Iatridou's (1996) analysis of the role of past tense morphology in counterfactuals; first, because my account owes a great deal to Iatridou's analysis of the pastcounterfactual connection, and second, because the two phenomena are similar in many respects and a comparison between them could be beneficial for a better understanding of the interaction between temporal and modal categories.

\subsection{The Past-Counterfactual Connection}

The past-counterfactual connection is manifested in the typological generalization that in many languages past tense morphology is linked to irrealis interpretation. The use of past tense in complements of wish, as in I wish I had more time, and in conditionals If I had more time, I would visit him, triggers the counterfactual inference I don't have (enough) time. Some accounts of the past-counterfactual connection treat past tense not as a primitive but merely as one of the manifestations of a more general semantic category REMOTE (cf. Isard 1974). Iatridou (1996) provides a formalization of the phenomenon in terms of EXCLUSION (or, rather, non-inclusion) frame operating over the domain of temporal intervals or possible worlds. In particular, she bases her analysis on the observation in Klein (1994) that the role of past tense is not to assert the existence of an eventuality prior to the moment of speech (or, to use his terminology, to assert that the TIME OF SITUATION (TSit) precedes the TIME OF UTTERANCE (TU)); if that were the case the use of past tense in examples like (25) would be at best infelicitous, as under the most natural interpretation the state of the book being in Russian extends through the moment of speech into the future. 
(25) (There was a book on the table.) The book was in Russian.

Past tense, according to Klein, simply signals that the interval for which the assertion is made, the TOPIC TIME (TT), is in the past relative to TU.

Iatridou proposes that the precedence relationship between the time intervals TT and TU, the fact that TT is not included in the interval TU, translates in the domain of modality into the assertion that the set of worlds quantified over extends beyond the set of epistemically accessible worlds, resulting in a counterfactual interpretation. The essence of Iatridou's proposal is represented in (26):
a. $\mathrm{D}(\mathrm{w}) \not \subset \mathrm{C}(\mathrm{w})$
b. $\mathrm{D}(\mathrm{t}) \not \subset \mathrm{C}(\mathrm{t})$

$\mathrm{D}(\mathrm{w})$ : the contextual domain of (world) quantification (Topic Sphere)

$\mathrm{C}(\mathrm{w})$ : the set of worlds that for all we know are the present world

$\mathrm{D}(\mathrm{t})$ : the contextual domain of (time) quantification (Topic Time)

$\mathrm{C}(\mathrm{t})$ : the set of times that for all we know are the present time

In other words, Iatridou accounts for the past-counterfactual connection by identifying the common semantic elements between the temporal and the modal category and by assigning past morphology a meaning underspecified as to the type of arguments involved, time intervals or possible worlds.

\subsection{The Common Semantic Structure of PE and the Present Perfect}

I assume a definition of the present perfect which is generally agreed upon, namely, that the present perfect asserts that the consequent state of an eventuality having culminated holds at the time of utterance (Moens 1987, Parsons 1990, Steedman 1994, Giorgi and Pianesi 1996, a.o. $)^{18}$. A sentence like John has left asserts that a certain state currently holds, which is the consequent state of the event of John's leaving. I propose that determining the meaning of indirect evidentiality are the following relationships introduced by the present perfect: (i) the consequent state of a past eventuality holding at a given time interval $t$, i.e. hold $(C S(e), t)$ and $\neg \operatorname{hold}(e, t)$, which is the contribution of the perfect; and (ii), the consequent state holding at the time of utterance, the contribution of the present tense. In the neo-Reichenbachian framework of Klein ${ }^{19}$, these translate into the requirements that TSit $\nsubseteq$ TT and TT $\subseteq$ TU. ${ }^{20}$ The fact that the core eventuality necessarily does not hold at TU is a distinguishing characteristics of the present perfect in comparison to the simple past: compare the (unmodified) present perfect in (27) to (25) above.

*The book has been in Russian.

I will next make the following assumptions. Adopting the general approach of defining correspondences in the temporal and modal domains, outlined in the previous subsection, I propose that the epistemic counterpart of an eventuality $e$ holding at an interval $t$, hold $(e, t)$, is the interpretation of a proposition $p$ (where $p$ results from giving $e$ a temporal specification) being known in a set of possible worlds. Let us further accept that corresponding to TU, we have the set of worlds epistemically accessible from the world of the speaker, $w_{s}$. Just like TU is a speakeranchored deictic center on the time line, $\bigcap \mathrm{f}\left(\mathrm{w}_{s}\right)$ is a speaker-anchored deictic center 
in $W$. Similarly, corresponding to TT, we have the Topic Sphere, the set of worlds in the domain of quantification.

The temporal contribution of the present perfect, namely the inference that the core eventuality does not hold in TU, or that TSit $\nsubseteq T \mathrm{TU}$, has as a correlate in the modal domain the inference that the set of worlds in which $p$ is known are excluded from $\bigcap f\left(w_{s}\right)$, i.e. they are epistemically inaccessible from $w_{s}$. In other words, the resulting interpretation is that the speaker has no direct evidence for $p$. This gives us part of the desired semantics. What we further need to do is to derive the presupposition of available indirect evidence by restricting the domain of quantification to only those worlds in which the speaker has indirect evidence for $p$. Recall that the present perfect has the interpretation that the consequent state of the core eventuality holds at TU. By our convention, this corresponds to an interpretation that the proposition $p^{\prime}$, derived by giving the state $C S(e)$ a temporal specification, is known in $\bigcap f(w)$. In other words, we arrive at the interpretation that in $w_{s} \in \bigcap f(w)$ the speaker knows the proposition $p^{\prime}=$ There are consequences/results of $\mathrm{p}$, or in other words, the speaker has indirect evidence for $p$. Recall at this point that the present tense morphology is crucial for the perfect of evidentiality interpretation (cf. examples (3)-(6) for the fact that the indirect evidentiality reading is not available in non-finite environments, as well as in the past and future perfects). It is now clear why this should be so. The fact that $C S(e)$ holds at TU and that $e$ does not hold at TU were both crucial, under the analysis proposed here, for deriving the interpretation of indirect evidentiality.

In summary, I argued in this subsection that the morphology of the present perfect contributes to either the temporal interpretation of propositions (by imposing a particular ordering between time intervals), or to their evidential status (by imposing particular relations between possible worlds). A compositional account was given to the contribution of the present perfect, as the role of both the perfect and the present tense morphology in deriving the modal interpretation was identified. Needless to say, many more important questions need to be addressed, in particular, both the notions of consequent state and of indirect evidence need a more exact formulation; similarly, further formalization is needed to reduce the correspondences identified here between the temporal and modal domains to a single meaning for the present perfect, which, given the right arguments, will produce as output a temporal or a modal construct. Still, I believe that even formulating these questions is an important step towards our better understanding of the links between temporal and modal categories, and as such the proposal advanced here is of relevance for theories of temporality and epistemic modality.

\subsection{Past as Counterfactual vs. Present Perfect as Evidential}

It is the goal of this subsection to briefly compare the two phenomena, known so far to exhibit a peculiar syncretism of temporal and modal categories. Both the past-counterfactual connection and the present perfect-evidential connection are characterized by temporal categories receiving in certain cases the interpretation of epistemic modals. Iatridou's (1996) analysis and the proposal developed here aim at providing an account of why it is possible for the past tense and the present perfect morphology, respectively, to take on a modal role; in answering this question, it turns out that the different temporal relations introduced by the past tense and 
the present perfect can account in a systematic way for the two, quite different interpretations, of counterfactuality and of indirect evidentiality. An interesting consequence of the accounts is that they predict that the counterfactual interpretation is an implicature (as pointed out in Stalnaker 1975 a.o.), whereas the evidential meaning is not. Recall, that in the case of the past tense, the temporal relation TT $\not \subset$ TU translates into the interpretation that the domain of quantification is not over the set of worlds epistemically accessible from $w_{s}$; it is predicated of worlds epistemically inaccessible from $w_{s}$ that they are $p$-worlds but no assertion is being made about $w_{s}$. It follows then, that the interpretation of counterfactuality, i.e. that $w_{\text {. }}$ is not a $p$-world, can only be an implicature (cf. Iatridou 1996). In the case of the present perfect, as TT $\subseteq \mathrm{TU}$, the corresponding modal relation is that of the Topic Sphere consisting of the epistemically accessible worlds; it thus follows that the meaning of available indirect evidence in $w_{s}$ cannot be an implicature.

\section{Conclusion}

In this paper I discussed a typological generalization concerning a connection between the present perfect and the category of evidentiality. After discussing the nature of evidentiality, and providing an analysis of indirect evidentials as epistemic modals of a sort, I offered an account of the present-perfect evidential connection based on the semantics of the present perfect. The proposal developed here has a number of implications. It makes finer distinctions in the family of epistemic modals and shows that natural language distinguishes between the types of evidence involved in epistemic reasoning. The proposal also reveals that the close relationship between modality and temporality extends beyond the conceptual similarities between the two and that temporal and modal structures in natural language, not just in the interpretative module, are in fact, composed of some of the same elements.

\section{Endnotes}

*I am extremely indebted to Sabine latridou for the numerous discussions and for her insightful comments and observations throughout the various stages of the writing of this paper. I furthermore want to thank Kai von Fintel and Yael Sharvit for their invaluable help regarding many of the issues presented here, and also Ginny Brennan, whose questions and suggestions helped improve the final draft. Thanks are also due to Filippo Beghelli, Dorit Ben-Shalom, Rajesh Bhatt, Robin Clark, Chung-hye Han, Manfred Krifka, Ellen Prince, Anoop Sarkar, and Mark Steedman. Errors and inconsistencies remain my responsibility.

${ }^{1}$ Languages, established so far to exhibit the phenomenon, are: Afro-Asiatic: Arabic (Negev Bedouin); Indo-European: Albanian, Bulgarian, Icelandic, Macedonian, Norwegian, Romani, Tajik; Niger-Congo: Dogon; South Caucasian: Georgian; Turkic: Turkish, Turkmen, and Uzbek; Uralic: Estonian, Finnish, Komi, Mari, Mańśi, Nenets, Udmurt. This list is based partly on Comrie 1976 (cf. references in Nedjalkov 1988, a.o.; note also that it is beyond the scope of this paper to provide comprehensive references to work on evidentiality, or even on the perfect-evidential connection). As he notes, areal influence from Turkic could probably account for the distribution of the phenomenon in Georgian, Bulgarian, and Albanian, but for some of the Uralic languages at least, it must be an independent development. 
${ }^{2}$ I use REPORT and INFERENCE simply as convenient labels for the range of interpretations allowed by indirect evidentials. My position is that we do not truly have a case of ambiguity here; the report reading is the weaker reading, according to which the speaker does not necessarily come to believe $p$; the inference reading is a stronger one, in which the speaker comes to believe $p$, yet does not have a justified belief, i.e., knowledge (cf. note 5) in $p$ (and that is why fails to assert $p$ ). The report/inference distinction will be discussed later in more detail.

${ }^{3}$ And finally, the interpretation is available even with sentences in the first person (as illustrated in (1)) which are pragmatically less favorable to such an interpretation.

${ }^{4} \mathrm{~A}$ summary of typical evidential distinctions in terms of source of evidence can be found in Willet (1988), a typological study of 38 languages with grammatical evidential systems, and also in Palmer (1986). There are languages, for instance, which mark finer distinctions within the categories of report (hearsay or folklore) and inference (inference based on observable results or on reasoning).

5In this paper I will use JUSTIFIED BELIEF and KNOWLEDGE interchangeably. Often in the philosophical literature a distinction is made between the two, knowledge being identified with justified true belief. Yet in natural language it is rarely, if at all, useful to talk about the truth of propositions in absolute terms since speakers are not omniscient. The term JUSTIFIED is not completely uncontroversial (see Gettier 1963, Feldman 1974); I use it in the sense of BASED ON SUFFICIENT EVIDENCE where what counts as sufficient and what not is context-dependent.

${ }^{6}$ Since Ev $p$ statements do not assert $p$, various entailments fail to obtain. For instance neither John apparently saw a unicorn/made a cake nor their perfect of evidentiality equivalents in (i) (from Bulgarian), entail the existence of unicorns or the coming into existence of a cake:

(i) Ivan vidjal ednorog/napravil torta. Ivan see-PE unicorn/ make-PE cake 'Ivan apparently saw a unicorn/made a cake.'

${ }^{7}$ Examples of PE here and elsewhere from now on are from Bulgarian. You may have noticed that in the PE example in $(11 \mathrm{~b})$ the auxiliary is missing. In Bulgarian, while in the 1st and 2nd persons the morphology of the PE is identical to that of the present perfect (cf. ( $1 \mathrm{~b})$ ), the 3rd person auxiliary is dropped in the case of PE (and retained in the present perfect) with only the past participle remaining. As pointed out to me by both Manfred Krifka and Sabine Iatridou, there is probably a semantic reason for the person distinctions; at this point though I have no satisfactory explanation.

In particular, compare the impossible continuations in (14) to the acceptable discourse in (i), illustrating a standard case of cancelling a conversational implicature:

(i) A: What do you think of John and Bill?

B: Bill is smart. $\sqrt{ }$ In fact/actually, John is smart, too

${ }^{9}$ Note also, that negation receives lower scope than the modal operator, just as it happens in 'ordinary' epistemic modals (cf. John mustn't be at home).

${ }^{10}$ It is crucial that apparently be interpreted as sentential modifier and not as a VPmodifier. In John didn't APPARENTLY pass the exam, apparently, especially when 
stressed, can be interpreted below negation. See Brennan 1993 for discussion of various syntactic and semantic issues concerning the scope of modal operators.

${ }^{11}$ That is, John believes that Mary is smart receives the interpretation that in all worlds compatible with what John believes in the current world, Mary is smart.

${ }^{12}$ Consider for instance the truth-conditions assigned to the present perfect by EXTENDED NOW theories (McCoard 1978, Dowty 1979, a.o.) according to which PR PERFECT $p$ is true if $p$ is true for some subinterval of an interval of which the present is the final subinterval.

${ }^{13}$ Cases of the actual interpretation being close to universal, rather than universal, can be analyzed along the lines of $(9 \mathrm{~b})$.

${ }^{14}$ The definition of ordering adopted here differs from Kratzer's formulation.

${ }^{15}$ What I mean by corresponding indicative forms is the following. The morphological system of the perfect of evidentiality is completely parallel to the indicative system. Corresponding to every indicative tense/aspect form is an indirect evidential form, with the correspondence being systematic - the present perfect morphology. In the case of indicative perfects, the corresponding evidentials have a double 'layer' of perfect morphology:

(i) Az sâm bil čel "Ana Karenina".

I be-1 SG, PRES be-P.PART read-P.PART Anna Karenina

'I have apparently read Anna Karenina.'

In (i), which is an indirect evidential based on an indicative present perfect, the auxiliary of the perfect is itself in the perfect of evidentiality morphology.

${ }^{16}$ Throughout this section 3rd person forms are used to differentiate between the present perfect and the perfect of evidentiality; recall that in Bulgarian the evidential forms do not have the auxiliary in the 3rd persons.

${ }^{17}$ It is possible to say Two plus two has always equaled four.

${ }^{18}$ The required aspectual type of the past eventuality and the exact notion of consequent state vary between some of the analyses.

${ }^{19}$ The neo-Reichenbachian framework is considered primarily for ease of comparison with Iatridou's analysis of the counterfactual role of past tense.

${ }^{20}$ The requirement that the core eventuality be culminated (or that TSit $\nsubseteq \mathrm{TT}$ ) is contradicted only by the existence of English perfects which take states as inputs as in I have known John since 1990; the possibility of this UNIVERSAL PERFECT, however, appears to be cross-linguistically restricted; therefore the relevance of (i) for the link with evidentiality is not necessarily compromised.

\section{References}

Brennan, V. (1993). Root and Epistemic Modal Auxiliary Verbs in English. Ph.D. thesis, University of Massachusetts at Amherst.

Chafe, W. and J. Nichols. (1986). Evidentiality: The Linguistic Coding of Epistemology. Norwood, NJ: Ablex.

Comrie, B. (1976). Aspect: An Introduction to the Study of Verbal Aspect and Related Problems. Cambridge: CUP. 
Dowty, D. (1979). Word Meaning in Montague Grammar. Dordrecht: Reidel.

Feldman, R. (1974). "An Alleged Defect in Gettier Counter-Examples", Australian Journal of Philosophy 52, 1, 68-69.

Gettier, E. (1963). "Is Justified True Belief Knowledge?", Analysis 23, 6, 121-123.

Giorgi, A and F. Pianesi. (1996). Tense and Aspect: from Semantics to Morphosyntax. Book manuscript. [To appear. Oxford University Press]

Iatridou, S. (1996). "The Grammatical Ingredients of Counterfactuality" ms. UPenn.

Isard, S. (1974). "What would you have done if" Theoretical Linguistics 1, 233-55.

Klein, W. (1994). Time in Language. London: Routledge.

Kratzer, A. (1986). "Conditionals”, CLS 1-15.

Kratzer, A. (1991). "Modality" in A. von Stechow and D. Wunderlich (eds.) An International Handbook of Contemporary Research, 639-650. Berlin de Gruyter.

Lyons, J. (1977). Semantics, vol. II. Cambridge: Cambridge University Press.

McCoard, R.W. (1978). The English Perfect: Tense Choice and Pragmatic Inferences, Amsterdam: North Holland.

Moens, M. (1987). Tense, Aspect, and Temporal Reference. Ph.D. diss. University of Edinburgh.

Nedjalkov, V. (1988). Typology of Resultative Constructions. Amsterdam/ Philadelphia: John Benjamins.

Palmer, F.R. (1986). Mood and Modality. Cambridge: Cambridge University Press.

Parsons, T. (1990). Events in the Semantics of English. Cambridge: MIT Press.

Slobin, D. and A. Akşu. (1982). "Tense, Aspect, and Modality in the Use of the Turkish Evidential" in P. Hopper (ed.) Tense-Aspect: Between Semantics and Pragmatics. Amsterdam: Benjamins, 185-200.

Stalnaker, R. (1975). "Indicative Conditionals", Philosophia 5, 269-286.

Steedman, M. (1994). "Temporality" in van Benthem, J. and A. ter Meulen (eds.) Handbook of Logic and Language. Elsevier Science B.V.

Willett, T. (1988) "A Cross-Linguistic Survey of the Grammaticization of Evidentiality" Studies in Language 12-1, 51-97. 